\title{
HUBUNGAN WAKTU PENYEMPROTAN PESTISIDA SEBELUM PANEN TERHADAP RESIDU PROFENOFOS DAN KARAKTERISTIK MUTU SAWI PAKCOY (Brassica rapa $\mathrm{L}$ )
}

\author{
I Made Prahadi Widnata Putra ${ }^{1}$, Bambang Admadi Harsojuwono ${ }^{2}$, I.G.A Lani Triani ${ }^{2}$ \\ ${ }^{1}$ Mahasiswa Jurusan Teknologi Industri Pertanian, Fakultas Teknologi Pertanian Unud \\ ${ }^{2}$ Dosen Teknologi Industri Pertanian, Fakultas Teknologi Pertanian Unud \\ Kampus Bukit Jimbaran, Badung, Bali \\ Email:wepe1995@gmail.com ${ }^{1}$ \\ E-mail koresponden: bambang.admadi@unud.ac.id ${ }^{2}$
}

\begin{abstract}
This research aims to 1) to know the correlation of different pesticide spraying time before harvest to the residual level of profenofos on the mustard pakcoy, 2) knowing the tendency of the relationship of different pesticide spraying time before harvest to the decrease of residual insecticidal content of profenofos and the quality characteristic of the mustard pakcoy. This research uses regression and correlation analysis, the factors used are the last spraying time 0 days, 2 days, 4 days, 6 days, 8 days, 10 days, before harvest. Each treatment was group in to 3 to obtain 18 experimental units. The parameters observed were the residual insecticide content of profenofos, pakcoy mustard characteristics and the relationship between the use of pesticide with the time interval of spraying on the residual content and the characteristics of the pakcoy. The results showed that the time of spraying before harvest was related to the residue of profenofos on the mustard pakcoy with treatment $0,2,4,6$, 8,10 days before harvest $0.001860 \mathrm{mg} / \mathrm{kg}, 0.000615 \mathrm{mg} / \mathrm{kg}, 0.000511 \mathrm{mg} / \mathrm{kg}, 0.000394 \mathrm{mg} / \mathrm{kg}$, $0.000279 \mathrm{mg} / \mathrm{kg}$, and $0.000270 \mathrm{mg} / \mathrm{kg}$. quality evaluation results with yellowish green to green color criteria, freshness of light and slightly damaged 1.6 to 3.75 (very damaged-undamaged). The result of correlation between the use of pesticide with the time of spraying on the residual insecticide content of profenofos and the characteristics of the quality of pakcoy mustard with the correlation coefficient value of 0.80 to the residual content, 0.96 to the color, 0.88 to freshness, and 0.97 to the damage value.
\end{abstract}

Keywords: Brassica rapa L, time of pesticide spraying, profenofos and residue

\section{PENDAHULUAN}

Ketahanan pangan mempunyai peran strategis dalam pembangunan nasional karena akses terhadap pangan dan gizi yang berkualitas untuk dikonsumsi merupakan hak azasi bagi manusia. Peningkatan konsumsi pada sayuran semakin meningkat, ini terjadi seiring dengan kesadaran manusia bahwa mengkonsumsi sayuran dapat memberikan manfaat yang baik terhadap kesehatan, dan juga akan berdampak pada peningkatan permintaan produk pertanian yang bersih dan aman dikonsumsi, di samping itu kualitas pangan dan gizi yang dikonsumsi merupakan sumber penting bagi pembentukan sumber daya manusia yang berkualitas (Nugrohati dan Untung, 1986). Salah satu bahan makanan yang berperan untuk kesehatan adalah sayuran, karena sayuran merupakan salah satu sumber mineral dan vitamin yang sangat dibutuhkan oleh manusia. 
Salah satu sayuran yang dikonsumsi oleh masyarakat saat ini adalah sawi pakcoy (Brassica rapa L) yaitu sayuran yang termasuk keluarga Brassicaceae atau sejenis kubis-kubisan. Sawi pakcoy sendiri dikenal berasal dari daratan Cina. Sawi pakcoy ini mulai dikembangkan di Indonesia, dengan sentra penanaman sayuran di Bali terbesar berada di Kabupaten Tabanan, yaitu sebesar 776 kwintal dan luas tanam sawi pakcoy 52 Ha (Dinas Pertanian Tanaman Pangan, 2013).

Berdasarkan hasil survai langsung dengan petani, didaerah Desa Baturiti, Kecamatan Baturiti. Dalam penanaman produk sawi pakcoy,sebagian besar petani menggunakan insektisida berbahan aktif profenofos, karena lebih efektif dan cepat mengendalikan hama, banyak kendala yang dijumpai oleh petani, salah satu kendala yang dihadapi adalah masalah hama terutama serangan dari ulat perusak daun (Plutella xylostella) dan penyakit busuk daun (phytoptora).

Kedua hama ini menyerang pada musim hujan, jika tidak dilakukan pengendalian hama akan menyebabkan tanaman sayuran tidak produktif sehingga mengakibatkan gagal panen (Sunarjono, 2003). Didalam bidang pertanian pestisida terbukti secara efektif dan efisien dalam mengendalikan hama, tetapi penggunan pestisida secara berlebihan dapat menimbulkan residu pada bahan makanan residu pestisida dalam makanan yang dikonsumsi sehari-hari, dalam jangka panjang dapat menimbulkan gangguan kesehatan seperti kejang otot, tremor, sakit kepala dan lain-lain (Isnawati, 2005). Ciri-ciri bahan pangan yang mengadung pestisida bisa terlihat secara kasat mata, mulai dari penampakan sayuran yaitu tampak lebih segar dan mengkilat (Suard, 2012). Pada penelitian Dibyantoro (1979) diperoleh residu Diazinon pada sayur selada akan menurun dari 6,7 mg/kg pada hari pertama setelah penyemprotan, menjadi $0,8 \mathrm{mg} / \mathrm{kg}$ pada hari ketujuh setelah penyemprotan. Berdasarkan hal tersebut maka akan dilakukan penelitian tentang hubungan waktu penyemprotan pestisida sebelum panen terhadap residu profenofos, dan karakteristik mutu sawi pakcoy.

\section{METODE PENELITIAN}

\section{Tempat dan Waktu Penelitian}

Penelitian dilakukan di kebun Sawi Pakcoy yang berada di Banjar Sekartaji, Desa Sesandan, Kecamatan Tabanan, Kabupaten Tabanan. Analisis laboratorium dilakukan di Forensik, POLDA BALI, dan Analisis Pangan Fakultas Teknologi Pertanian Universitas Udayana, waktu pelaksanaan penelitian bulan Mei 2017 sampai Oktober 2017.

\section{Bahan dan Alat Penelitian}

Bahan baku yang digunakan dalam penelitian ini adalah Sawi Pakcoy, yang diperoleh dari Banjar Sekartaji. Bahan-bahan yang kimia yang diperlukan adalah pelarut aseton 99,75\% (Merck), diklorometan (Merck), petroleum eter (Merck), dan florisil (particle size 1,15093 mm, for column chromatography 5975C inert MSD) dan insektisida (berbahan aktif profenofos). Peralatan yang digunakan adalah blender, Erlenmeyer (pyrex) (ukuran $125 \mathrm{ml}$ dan $250 \mathrm{ml}$ ), beaker glass (pyrex) (ukuran $25 \mathrm{ml}$ dan $50 \mathrm{ml}$ ), corong, kertas saring, alumunium foil, gelas ukur (Iwaki) (ukuran $10 \mathrm{ml}$ dan $100 \mathrm{ml}$ ), pipet mikro (Socorex), timbangan (Mettle Toledo), vial plastik untuk eluat, evaporator 
(airflow monitor, Mach-Aire ltd), tabung reaksi (Iwaki), kolom kromatografi, dan Gas Chromatography (5975C inert MSD).

\section{Pelaksanaan Percobaan}

Penelitian ini mencoba mencari hubungan waktu Penyemprotan pestisida sebelum panen terhadap residu profenofos dan karakteristik mutu sawi pakcoy faktor yang digunakan terdiri atas 6 perlakuan waktu penyemprotan sebelum panen 0,2,4,6,8,10 hari sebelum panen, dan dilakukan ulangan sebanyak 3 kali dari pelaksanaan tersebut diperoleh 18 unit percobaan kemudian akan dianalisis menggunakan metode regresi dan korelasi.

\section{Pelaksanaan Penelitian}

\section{Penanaman}

Pada saat tanaman sawi pakcoy berumur 10 hari (bibit yang berdaun 4-5 helai) dipindahkan dari tempat penyemaian ke lahan yang telah disiapkan, pemeliharaan tanaman dilakukuan dengan penyiraman dan penyemprotan menggunakan insektisida merek curacron berbahan aktif kandungan Profenofos untuk mencegah serangan hama. Pada umur 17 hari dilakukan penyemprotan menggunakan insektisida merek curacron dan selanjutnya penyemprotan dilakukan tergantung pada hama yang menyerang. Sawi pakcoy dapat dipanen setelah berumur sekitar 40 hari. Sebelum pemanenan, sawi pakcoy pada umur 30 hari petani melakukan penyemprotan pestisida terakhir sebagai perlakuan, dengan interval waktu 0 hari, 2 hari, 4 hari, 6 hari, 8 hari, 10 hari sebelum panen.

\section{Pemanenan}

Sawi pakcoy dapat dipanen saat berumur 40 hari, tanaman yang layak panen memiliki daun yang tumbuh subur berwarna hijau segar, pangkal daun tampak sehat, serta ketinggian tanaman seragam dan merata.

\section{Sampel}

Sawi pakcoy yang di ambil dari lahan petani, yang telah diberikan perlakuan penyemprotan pestisida sebelum panen dengan interval waktu yaitu : 0 hari, 2 hari, 4 hari, 6 hari, 8 hari, 10 hari sebelum panen. Pengambilan sampel sawi pakcoy di lahan petani, lahan sawi pakcoy yang terlebih dahulu dibagi enam perlakuan, sehingga memperoleh enam sampel sawi pakcoy dari masing-masing perlakuan, kemudian sampel tersebut di masukkan ke wadah plastik dan selanjutnya dilakukan analisis laboratorium.

\section{Variabel yang Diamati}

Analisis residu pestisida dikerjakan berdasarkan Harun (2005) yang di modifikasi (2013) dengan menggunakan Gas Chromatography. Tahapan analisis meliputi : ekstraksi sampel, pemurnian (clean up), analisis kuantitatif (perhitungan kadar residu), dan karakteristik mutu sawi pakcoy.

\section{Analisis Residu}

Pembuatan standar diperoleh dengan melarutkan insektisida berbahan aktif profenofos $16,7 \mu 1$ kedalam $10 \mathrm{ml}$ aseton sehingga diperoleh larutan standar profenofos $1000 \mathrm{ppm}$. Konsentrasi larutan standar yang digunakan adalah $0 \mathrm{ppm}, 0,5 \mathrm{ppm}, 1 \mathrm{ppm}$, dan $3 \mathrm{ppm}$. Larutan standar sebanyak $2 \mu \mathrm{l}$ 
diinjeksikan ke Gas Chromatography diperoleh area standar, Kemudian dibuat kurva linearnya dan diperoleh persamaan.

\section{Ektraksi Sampel}

Sampel sawi pakcoy yang telah dipanen, kemudian di potong-potong selanjutnya di timbang sebanyak 25g. Sampel ditambahkan petroleum eter (PE) sebanyak $50 \mathrm{ml}$ dan diklorometan (DM) sebanyak $50 \mathrm{ml}$, kemudian di blender selama 2 menit. Hasil blenderan dimasukkan ke dalam beaker glass kemudian ditutup dengan menggunakan alumunium foil, lalu didiamkan selama 1 jam agar fase organik I dan fase ampas terpisah. Setelah terpisah dimasukkan ke dalam beaker glass yang berbeda dan akan diuapkan dievavorasi sampai volumenya $50 \mathrm{ml}$.

\section{Pemurnian (Clean Up)}

Ektrak ( $2 \mathrm{ml})$ dimasukkan ke dalam kolom kromatografi yang telah diisi florisil (20 ml). Elusi dengan larutan petroleum eter (PE) sebanyak $50 \mathrm{ml}$. Eluat (hasil permunian $20 \mathrm{ml}$ ) ditampung digelas beaker glass $25 \mathrm{ml}$, lalu diuapkan sampai sedikit kering $(1 \mathrm{ml})$, larutan dipindahkan ke dalam vial plastik dengan bantuan larutan aseton sampai volume $1 \mathrm{ml}$, dilanjutkan dengan sentrifuse kemudian disiapkan untuk pembacaan pada Gas Chromatography.

\section{Analisis kuantitatif (Perhitungan kadar residu)}

Gas Chromatography dengan kondisi siap pakai (standar) pada suhu kolom $200^{\circ} \mathrm{C}$, suhu injector $230^{\circ} \mathrm{C}$, kecepatan alir $\mathrm{N}_{2} 40 \mathrm{ml} /$ menit, $\mathrm{H}_{2} 1,3 \mathrm{~kg} / \mathrm{cm}^{2}$ dan tekanan udara $.1 \mathrm{~kg} / \mathrm{cm}^{2}$. Analisis dilakukan pada kondisi tersebut dengan menyuntikkan $4 \mu 1$ larutan sampel ke dalam Gas Chromatography dan menghasilkan kromotogram dengan area tertentu. Konsentrasi residu insektisida dalam sampel dapat dihitung dari grafik kromatogram yang dihasilkan, kemudian dibandingkan dengan kromatogram standar. Variabel yang diamati dalam penelitian ini adalah kadar residu insektisida pada sawi pakcoy kemudian dibandingkan dengan nilai BMR pestisida pada hasil pertanian (Badan Standarisasi Nasional, 2008).

\section{Analisis Sensoris}

Uji organoleptik ini dilakukan pengamatan terhadap penampakan warna, kesegaran, dan nilai kerusakan pada sawi pakcoy panelis diminta untuk memberikan penilian terhadap warna, kesegaran, dan nilai kerusakan pada sawi pakcoy panelis yg digunakan adalah dari kalangan mahasiswa Fakultas Teknologi Pertanian, dari data yang diperoleh kemudian dihitung untuk mencari nilai rata-rata warna, kesegaran dan kerusakan pada sawi pakcoy kemudian dianalisis menggunakan metode regresi dan korelasi.

\section{Analisis Data}

Untuk mengetahui ada atau tidaknya hubungan antara penggunaan insektisida dan waktu penyemprotan pestisida terhadap kadar residu profenofos karakteristik mutu pada sawi pakcoy (Brassica rapa $\mathrm{L}$ ) dalam penelitian ini maka digunakan analisis regresi dan korelasi dengan bantuan program komputer EXCEL. 


\section{HASIL DAN PEMBAHASAN}

\section{Hubungan Waktu Penyemprotan Pestisida Sebelum Panen Terhadap Kadar Residu Pada Sawi Pakcoy.}

Hasil analisis regresi, koefisien korelasi dan determinasi pada hubungan waktu penyemprotan pestisida sebelum panen terhadap kadar residu pada sawi pakcoy seperti terlihat pada Gambar 1 .

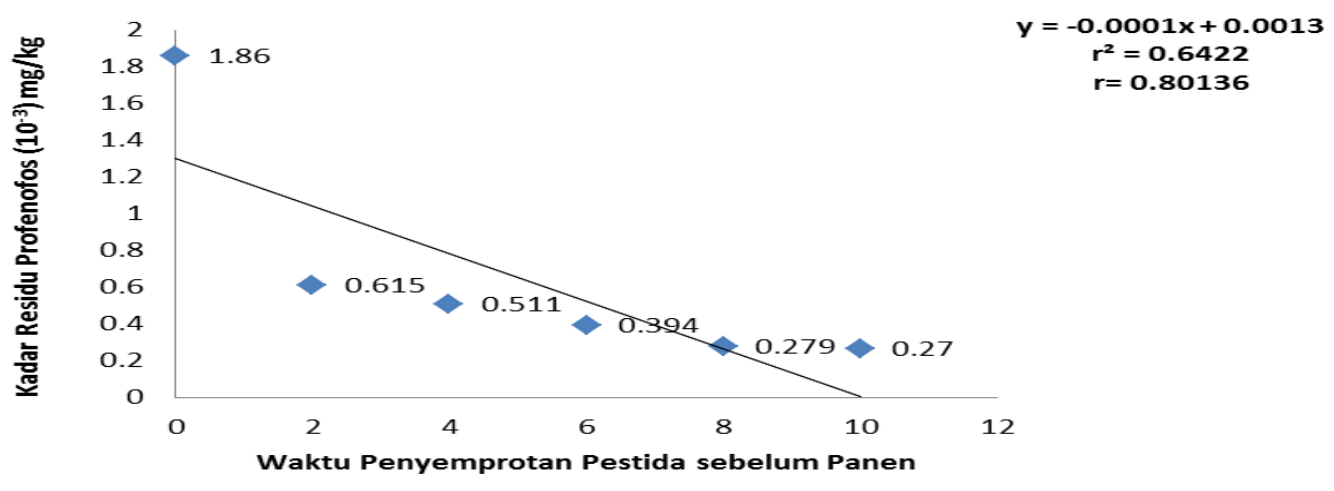

Gambar 1. Grafik hubungan antara waktu penyemprotan pestisida sebelum panen terhadap kadar residu insektisida profenofos pada sawi pakcoy.

Gambar 1 menunjukkan hubungan waktu penyemprotan pestisida sebelum panen terhadap kadar residu profenofos pada sawi pakcoy memperoleh persamaan regresi $Y=-0,0001 X+0,0013$ dengan nilai koefisien korelasi sebesar $(r)=0,80$ dan koefisien determinasi $(r 2)=0,64$. Dari persamaan regresi yang diperoleh $\mathrm{Y}=-0,0001 \mathrm{X}+0,0013$. Semakin panjang interval waktu penyemprotan sebelum panen, maka residu mengalami penurunan. Hal ini disebabkan oleh semakin lama interval waktu penyemprotan pestisida sebelum panen, sehingga menyebabkan sawi pakcoy semakin lama terkena pengaruh faktor lingkungan baik oleh air hujan, suhu, sinar matahari yang mengakibatkan penurunan kadar residu. Penurunan diakibatkan oleh air hujan dimana profenofos bersifat larut dalam air, sehingga profenofos terbawa oleh air hujan, rata-rata penurunaan kadar residu profenofos pada sawi pakcoy sebesar $0,000655 \mathrm{ml} / \mathrm{kg}$, tingkat koefisien korelasi $\mathrm{r}=0,80$ yang artinya memiliki hubungan yang sangat kuat antara waktu penyemprotan pestisida sebelum panen dengan kadar residu profenofos pada sawi pakcoy, dan memiliki nilai koefisien determinasi sebesar $r 2=0,64$ yang berarti 64 persen, kadar residu insektisida profenofos dipengaruhi oleh waktu penyemprotan pestisida sebelum panen, sedangkan 36 persen, kadar residu profenofos yang disebabkan oleh beberapa faktor lain, sesuai data yang diperoleh dari Badan Meteorologi dan Geofisika Wilayah III periode bulan Juni Agustus tahun 2017 menunjukan di Kecamatan Penebel, jumlah curah hujan rata-rata 97 mm, dan serta kadar residu mengalami penurunan karena sinar matahari akan mempercepat penguraian insektisida (Triani,2005). 


\section{Hubungan Waktu Penyemprotan Pestisida Sebelum Panen Terhadap Warna Sawi Pakcoy.}

Hasil analisis regresi, koefisien korelasi dan determinasi pada hubungan waktu penyemprotan pestisida sebelum panen terhadap warna pada sawi pakcoy seperti terlihat pada Gambar 2.

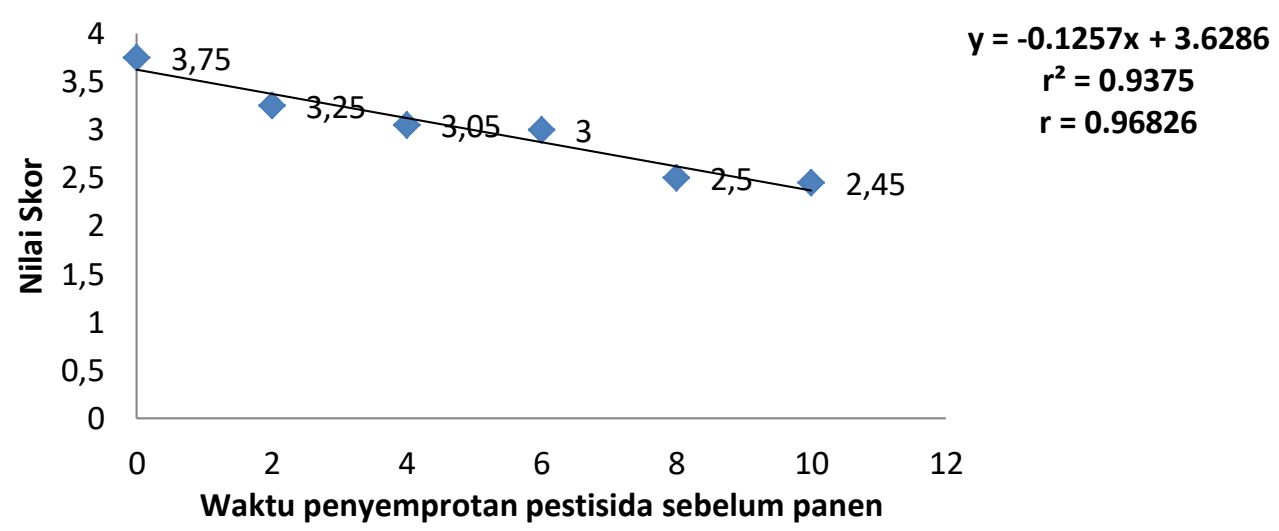

Gambar 2. Grafik hubungan antara waktu penyemprotan pestisida sebelum panen terhadap warna sawi pakcoy.

Gambar 2 menunjukkan hubungan waktu penyemprotan pestisida sebelum panen terhadap warna pada sawi pakcoy memperoleh persamaan regresi sebesar $\mathrm{Y}=-0,1257 \mathrm{X}+3,6286$, dengan nilai koefisien korelasi $(r)=0,96$ dan koefisien determinasi $\left(r^{2}\right)=0,93$. Dari persamaan regresi $Y=-0,1257 X$ $+3,6286$. Semakin panjang interval waktu penyemprotan sebelum panen, maka terjadi penurunan mutu warna. Hal ini disebabkan oleh interval waktu penyemprotan pestisida sebelum panen yang mengakibatkan metabolisme tumbuhan tanaman terganggu oleh hama sehingga dalam proses pembentukan klorofil menjadi tidak sempurna, nilai rata-rata penilaian panelis berkisar antara 2,453,75 (hijau kekuningan sampai hijau). Tingkat koefisien korelasi $r=0,96$ yang artinya memiliki hubungan yang sangat kuat antara waktu penyemprotan pestisida sebelum panen dengan warna pada sawi pakcoy dan memiliki nilai koefisien determinasi sebesar $r^{2}=0,93$ yang berarti 93 persen, warna dipengaruhi oleh waktu penyemprotan pestisida sebelum panen, sedangkan 7 persen disebabkan oleh faktor lain. Menurut Santoso dan Purwoko (1995) menyatakan bahwa komoditas holtikultura merupakan jaringan hidup yang terus melakukan perubahan fisiologi merupakan proses pematangan organ merupakan suatu rangkaian proses perubahan warna, cita rasa.

\section{Hubungan Waktu Penyemprotan Pestisida Sebelum Panen Terhadap Kesegaran Sawi Pakcoy.}

Hasil analisis regresi, koefisien korelasi dan determinasi pada hubungan waktu penyemprotan pestisida sebelum panen terhadap kesegaran pada sawi pakcoy seperti terlihat pada Gambar 3 . 


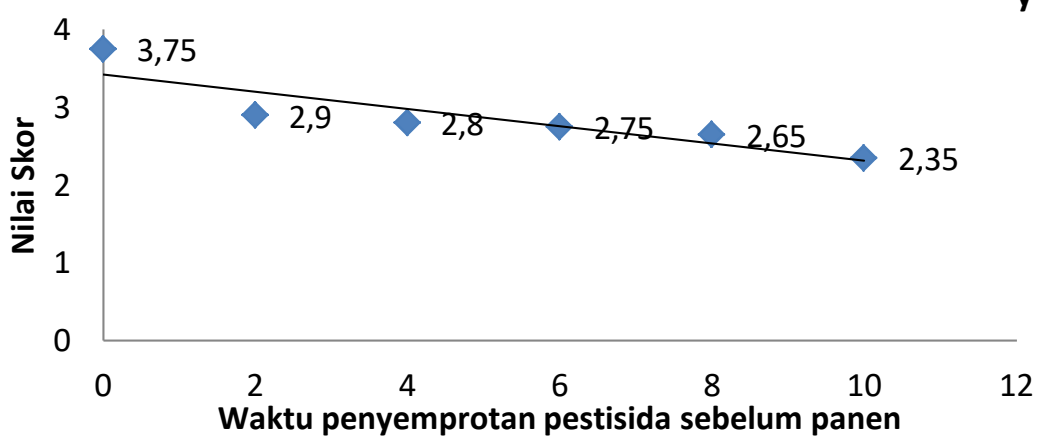

$y=-0.1114 x+3.4238$

$r^{2}=0.7807$

$r=0.88355$

Gambar 3. Grafik hubungan antara waktu penyemprotan pestisida sebelum panen terhadap kesegaran pada sawi pakcoy.

Gambar 3 menunjukkan hubungan waktu penyemprotan pestisida sebelum panen terhadap kesegaran pada sawi pakcoy memperoleh persamaan regresi yaitu $Y=-0,1114 \mathrm{X}+3,4238$, dengan nilai koefisien korelasi $(r)=0,88$ dan nilai koefisien determinasi $\left(r^{2}\right)=0,78$. Dari persamaan regresi $Y=-$ $0,1114 X+3,4238$. Semakin panjang interval waktu penyemprotan sebelum panen maka terjadi penurunan mutu kesegaran. Hal Ini disebakan oleh interval waktu penyemprotan pestisida sebelum panen dan proses dalam pemanenan dan pengemasan sawi pakcoy nilai rata-rata panelis berkisar antara 2,35-3,75 (layu - segar). Tingkat koefisien korelasi r= 0.88 yang artinya memiliki hubungan yang sangat kuat antara waktu penyemprotan pestisida sebelum panen dengan kesegaran pada sawi pakcoy, dan memiliki nilai koefisien determinasi sebesar $r^{2}=0,78$ yang berarti 78 persen, kesegaran dipengaruhi oleh waktu penyemprotan pestisida sebelum panen, sedangkan 22 persen, di sebabkan oleh faktor lain. kehilangan kandungan air pada sawi pakcoy akan mudah mengalami kelayuan.

\section{Hubungan Waktu Penyemprotan Pestisida sebelum Panen terhadap Kerusakan Sawi Pakcoy.}

Hasil analisis regresi, koefisien korelasi dan determinasi pada hubungan waktu penyemprotan pestisida sebelum panen terhadap kerusakan pada sawi pakcoy seperti terlihat pada Gambar 4.

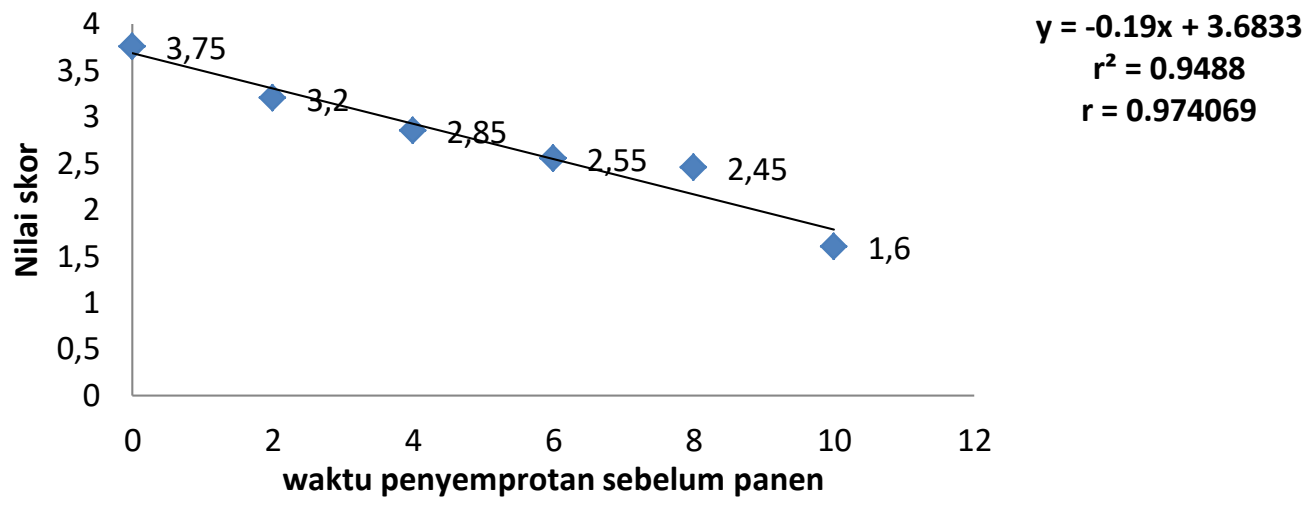

Gambar 4. Grafik hubungan antara waktu penyemprotan pestisida sebelum panen terhadap kerusakan pada sawi pakcoy. 
Gambar 4 menunjukkan hubungan waktu penyemprotan pestisida sebelum panen terhadap kerusakan pada sawi pakcoy memperoleh persamaan regresi yaitu $\mathrm{Y}=-0,19 \mathrm{X}+3,6833$, dengan nilai koefisien korelasi $(r)=0,97$ dan nilai koefisien determinasi $(r 2)=0,94$. Persamaan regresi $Y=-0,19 X+$ 3,6833,yang berarti semakin panjang interval waktu penyemprotan sebelum panen, maka terjadi penurunan nilai kerusakan. Hal ini disebabkan oleh interval waktu penyemprotan pestisida sebelum panen maka pestisida yang diberikan akan berkurang sehingga menyebakan serangga menyerang sawi pakcoy. Nilai rata-rata panelis berkisar antara 1,6-3,75 (sangat rusak-tidak rusak) Tingkat koefisien korelasi $\mathrm{r}=0,97$ yang artinya memiliki hubungan yang sangat kuat antara waktu penyemprotan pestisida sebelum panen dengan kerusakan pada sawi pakcoy dan memiliki nilai koefisien determinasi sebesar r2 = 0,94 yang berarti 94 persen, kerusakan dipengaruhi oleh waktu penyemprotan pestisida sebelum panen yang menyebabkan sawi lebih mudah terekena hama, sedangkan 6 persen, di sebabkan oleh faktor lain seperti aktivitas serangan serangga pada sawi pakcoy yang menyebabkan kerusakan fisik pada sawi pakcoy. Kerusakan yang terjadi pada sawi pakcoy dengan perlakuan waktu 0, 2, 4, 6, 8, 10 hari penyemprotan pestisida sebelum panen dapat dilihat pada Gambar 5, Gambar 6, Gambar 7, Gambar 8, Gambar 9, dan Gambar 10.

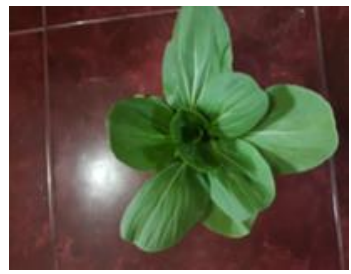

Gambar. 5

( 0 hari sebelum panen)

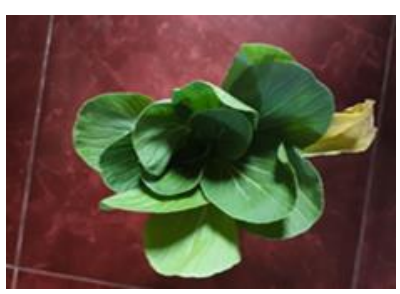

Gambar. 8

(6 hari sebelum panen)

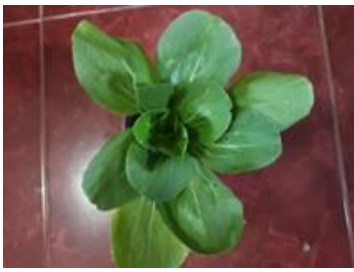

Gambar. 6

(2 hari sebelum panen)

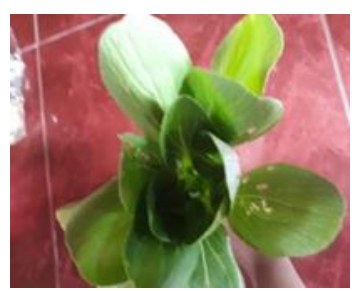

Gambar. 9

(8 hari sebelum panen)

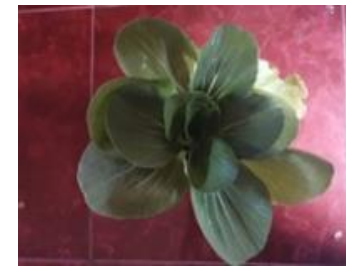

Gambar. 7

(4 hari sebelum panen)

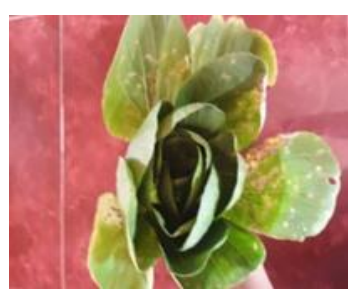

Gambar. 10

(10 hari sebelum panen)

Keterangan : Kerusakan yang terjadi pada sawi pakcoy dengan perlakuan waktu 0, 2, 4, 6, 8, 10 hari penyemprotan pestisida sebelum panen. 


\section{Penentuan Perlakuan Penyemprotan Pestisida Sebelum Panen.}

Hasil Penentuan perlakuan Penyemprotan Pestisida sebelum panen dapat dilihat pada Tabel 1.

Tabel 1. Hasil perlakuan kadar residu dan nilai karakteristik mutu sawi pakcoy

\begin{tabular}{ccccc}
\hline $\begin{array}{c}\text { Perlakuan } \\
\text { Hari }\end{array}$ & $\begin{array}{l}\text { Kadar } \\
\text { Residu }\end{array}$ & \multicolumn{3}{c}{ Hasil Uji Sensoris } \\
\cline { 3 - 5 } & $(\mathbf{m g} / \mathbf{k g})$ & Warna & Kesegaran & Kerusakan \\
& & & & \\
\hline 0 & 0,001860 & 3,75 & 3,75 & 3,75 \\
2 & 0,000615 & 3,25 & 2,9 & 3,2 \\
4 & 0,000511 & 3,05 & 2,8 & 2,85 \\
6 & 0,000394 & 3 & 2,75 & 2,55 \\
8 & 0,000279 & 2,5 & 2,65 & 2,45 \\
10 & 0,000270 & 2,45 & 2,35 & 1,6 \\
\hline
\end{tabular}

Pada Tabel 1 menunjukkan untuk kadar residu terendah ditunjukkan pada perlakuan 10 hari sebelum panen sebesar $0,000270 \mathrm{mg} / \mathrm{kg}$, menunjukan masih dibawah BMR sayur yaitu $0,1 \mathrm{mg} / \mathrm{kg}$. (Badan Standarisasi Nasional, 2008) dan masih aman untuk dikonsumsi. Sedangkan perlakuan terbaik untuk karakteristik mutu sawi pakcoy yakni perlakuan 0 hari sebelum panen dengan warna 3,75 (hijau muda sampai hijau), kesegaran 3,75 (sedikit layu sampai segar), dan nilai kerusakan 3,75 (biasa sampai tidak rusak), untuk kadar residunya juga masih dibawah BMR sebesar 0,001860 mg/kg.

\section{KESIMPULAN DAN SARAN}

\section{Kesimpulan}

1. Hubungan antara waktu penyemprotan pestisida sebelum panen dengan kadar residu profenofos adalah sangat kuat dengan nilai $r=0,80$ persamaan regresi $Y=-0,0001 X+0,0013$. Hubungan antara waktu penyemprotan pestisida sebelum panen terhadap karakteristik mutu sawi pakcoy (warna, kesegaran, kerusakan) adalah sangat kuat dengan nilai $r=$ warna 0,96, kesegaran 0,88, kerusakan 0,97 dengan persamaan regresi secara berurutan $\mathrm{Y}=-0,1257 \mathrm{X}+3,6286, \mathrm{Y}=-0,1114 \mathrm{X}$ $+3,4238$, dan $Y=-0,19 \mathrm{X}+3,6833$.

2. Waktu penyemprotan pestisida sebelum panen mempunyai kecenderungan menurunan terhadap kadar residu insektisida profenofos dan karakteristik mutu pada sawi pakcoy, rata-rata penurunan kadar residu profenofos pada sawi pakcoy sebesar $0,000655 \mathrm{ml} / \mathrm{kg}$ dan secara linear sebesar $0,0001 \mathrm{X}$ satuan. dan penurunan mutu sawi pakcoy berurutan secara linear sebesar untuk warna $=-$ $0,1257 \mathrm{X}$, kesegaran $=-0,1114 \mathrm{X}$, kerusakan $=-0,19 \mathrm{X}$.

\section{Saran}

1. Diharapkan petani menerapkan waktu penyemprotan pestisida sebelum panen agar kadar residu yang di tinggalkan sebelum panen rendah, dan perlu adanya penelitian lebih lanjut terhadap pencampuran konsentrasi pestisida saat melakukan penyemprotan pestisida. 
2. Konsumen juga diharapkan agar mencuci sayurannya terlebih dahulu sebelum di konsumsi, agar kandungan residu insektisda yang terdapat pada sayuran berkurang. Dan konsumen juga lebih memahami bahwa sayuran fisik yang terlihat sangat segar maka kadar residu yang terkandung cukup besar.

\section{DAFTAR PUSTAKA}

Badan Standardisasi Nasional. 2008. Batas Maksimum Residu Pestisida Pada Hasil Pertanian. Badan Standardisasi Nasional, SNI7313:2008. Jakarta.

Djojosumarto, P. 2008. Pestisida dan Aplikasinya. Agromedia Pustaka, Jakarta.

Harsojuwono, B.A., I.W Arnata., dan G.A.K.D. Puspawati. 2011. Rancangan Percobaan Teori Aplikasi SPSS dan Excel. Penerbit Lintas Kata Publishing. Malang.

Haryanto. 2006. Teknik Budidaya Sayuran Pakcoy (Sawi Mangkok). Penebar Swadaya, Jakarta.

Irie, .2007. Pestiside residues in food, report of the JMPR 2007, FAO plant production and protection paper, 191, pp 210 pages 1357.

Moekasan, T. K. 2012. Penerapan ambang pengendalian organisme pengganggu tumbuhan pada budidaya bawang merah dalam upaya mengurangi penggunaan pestisida. Jurnal Hortikultura, 22(1), 47-56.

Nugrohati, S. dan K. Untung. 1986. Pestisida dalam Sayuran. Seminar Keamanan Pangan dalam Pengolahan dan Penyajian. Yogyakarta 1 - 3 September.

Oginawati, K. 2008. Sanitasi Makanan dan Minuman. Penerbit Institut Teknologi Bandung Press. Bandung.

Sarjono, H. H. 2003. Seri Agribisnis, Bertanam 30 Jenis Sayur. Penebar swadaya, Jakarta.

Soekarto, S.T. 1985. Penelitian Organoleptik Untuk Industri Pangan dan Hasil pertanian. Bharata Karya Aksara. Jakarta.

Suard, M. 2012. Bahaya sayur dan Buah Berpestida. http://ffarmasi.unuand.ac.id/berita/abam/989/apa-bahaya-sayur-dan-buah-berpestida-muslim-suardi. Diakses pada tanggal 20 April 2017.

Sugiyono. 2011. Statistik Untuk Penelitian. Penerbit Alfabeta, Bandung.

Sutirman. 2011. Budidaya Tanaman Sayuran Sawi di Dataran Rendah Kabupaten Serang Provinsi Banten. Banten.

Suwarjana, P,E. 2015. Aplikasi Commodity System Assessment Method dalam distribusi sawi pakcoy (Brassica rapa L) dari petani di Kecamatan Baturiti 24 ke pengecer. Laporan Tugas Akhir Mahasiswa S1 (Skripsi). Tidak dipublikasikan PS. Teknologi Industri Pertanian, Fakultas Teknologi Pertanian, Universitas Udayana. Jimbaran - Badung.

Triani, I, G, A, L., I. B. W. Gunam, dan L. P. Wrasiati. 2013. Analisis Residu Insektisida pada Kacang Panjang (Vigna sinensis) yang Dihasilkan di Kabupaten Tabanan. Laporan Akhir Penelitian Hibah Bersaing, Universitas Udayana. Denpasar. 
Triani, I, G, A, L. 2005. Residu Insektisida Sidazinon pada Kacang Panjang (Vigna sinensis) yang Dihasilkan di Kabupaten Tabanan. Laporan Penelitian Program Studi Ilmu Lingkungan. Tesis S2. Tidak dipublikasikan. Program Magister Ilmu Lingkungan, Universitas Udayana. Denpasar.

Williams, U, dan Peregrine. 1993. Produksi Sayuran di Daerah Tropika. Gadjah Mada Press, Yogyakarta. 